\title{
aniki
}

Revista Portuguesa da Imagem em Movimento

Portuguese Journal of the Moving Image

\section{Adaptação da Obra Literária ao Cinema: A Validação Autoral da Realizadora Mulher Érica Faleiro Rodrigues ${ }^{1}$}

Shelley Cobb. 2015. Adaptation, Autorship, and Contemporary Women Filmmakers. Palgrave Macmillian. 167 pp. ISBN 978-0-230-28384-8

Shelley Cobb tem publicado nas áreas do cinema feito por mulheres, do pós-feminismo e dos estudos sobre média. Numa época em que os festivais dedicados ao cinema no feminino se multiplicam, e em que este ainda se encontra longe dos grandes orçamentos e prémios internacionais, torna-se pertinente falar do papel da mulher realizadora e sobre o impacto comercial do seu trabalho. Neste livro, Cobb propõe-se analisar o modo como a mulher cineasta adapta a obra literária de autoras mulheres, numa duplicação da criação artística no feminino - como esta passagem da obra literária no feminino para o objeto cinematográfico feito por mulheres reflete, não só, questões do feminino, que se desdobram e multiplicam, como produz diferenças na representação desse mesmo feminino e serve como veículo de validação autoral.

$\mathrm{Na}$ introdução, Cobb debruça-se sobre a importância da legitimidade das mulheres como criadoras de cultura, começando pela questão da validação autoral. Argumenta a autora que a colaboração com outras mulheres levaria a uma validação mais orgânica da autoria; lembrando a problemática de como tão poucas mulheres realizam filmes - uma observação válida, mas necessitada de aprofundamento, já que a escassez de cineastas mulheres não se distribui igualmente por todos os géneros cinematográficos. Cobb assume o seu livro como um estudo de filmes que considera produtos de um período pós-feminista, expressando que o contexto que permitira o financiamento de filmes feministas nas décadas de setenta e oitenta já não existe.

O primeiro capítulo centra-se numa questão nodal do livro Um Quarto que Seja Seu, de Virginia Woolf: a impossibilidade da autoria no feminino e de uma Judith Shakespeare, que, ao contrário do seu famoso irmão, morreria nova, sem nunca ter escrito uma palavra. Cobb argumenta que esta ideia da autoria impossível de uma Judith Shakespeare mantém premência no mundo do cinema, prosseguindo ${ }^{1}$ Doutoranda em Birkbeck College, University of London, School of Arts,
Department of Cultures and Languages, WC1H 0PD, London, United Kingdom. 
com o modo como os Óscares e o Festival de Cannes não têm, regra geral, elegido candidatas ao prémio de realização e consagrado realizadoras. Cobb refere como este apagamento do feminino torna qualquer mulher nomeada ou premiada num 'caso' absolutamente notável. Aborda-se o filme de Sally Potter, Orlando, de 1993, baseado no livro homónimo de Virginia Woolf, e o modo como uma espécie de linhagem matriarcal é posta em prática. É aqui, neste capítulo, que Cobb lembra como o trabalho de mulheres cineastas se foi perdendo ao longo da história do cinema. A questão colocada por Virgínia Woolf é a de Judith Shakespeare se ter visto impossibilitada de deixar obra por o trabalho intelectual de uma mulher do seu tempo ser considerado irrelevante. Cobb, por sua vez, transporta esta problemática para o cinema, trazendo algum humor negro ao texto, quando substitui Judith Shakespeare por Judith Hitchcock, a irmã de Alfred Hitchcock.

Virginia Woolf é central, relembrando-se a relevância das questões que colocou sobre a possibilidade de se ser autor no feminino. Cobb, aliás, estabelece Woolf como uma pioneira da problemática do feminino, e não elude certas questões mais problemáticas, como a da identificação e da desidentificação com causas feministas.

Shelley Cobb relembra o ciclo vicioso da realização de cinema no feminino: o baixo número de realizadoras como pretexto (ainda hoje em dia o financiamento é feito maioritariamente no masculino) para se recusarem fundos, ou seja, como aval de que o cinema feito por mulheres não traz viabilidade económica.

Depois de se focar em Orlando, de Sally Potter, Cobb parte para um terreno onde se sente mais confortável, o das adaptações da obra literária de Jane Austen. Aqui, começa por se debruçar no filme Mansfield Park, de Patricia Rozema, para de seguida se inclinar sobre o fenómeno (ocorrido nos anos noventa) da produção baseada na obra de Jane Austen. No caso de Patricia Rozema, a questão do valor autoral de quem realiza filmes a partir de adaptações torna-se complexa, por a diretora declarar expressamente "Não [ser Mansfield Park] um filme de Jane Austen, [mas sim] um filme de Patricia Rozema”.

No segundo capítulo, intitulado "Adaptação ou Morte: As Ameaças à Autoria de Mulheres", o estigma do feminismo, sob a forma do "fardo da representação", é trazido à superfície, através da constatação de muitas realizadoras preferirem, e defenderem até, a invisibilidade do (seu) género enquanto autoras; enfatizando-se a forma como o tabu do feminismo é internalizado e, desta forma, persiste no discurso das realizadoras que se afirmam ou se pretendem afirmar profissionalmente. Cobb toca na despolitização; mas também na ambiguidade de uma linguagem mediática que papagueia a igualdade de género no trabalho, ao mesmo tempo que omite as realidades do desequilíbrio na vida profissional. 
Neste segundo capítulo, Cobb prossegue abordando as adaptações ao cinema de obras literárias contemporâneas - The Weight of Water, de Sarah Crosson, Morven Caller, de Alan Warner, e In the Cut, de Susanna Moore -, que deram origem às obras cinematográficas homónimas de Kathryn Bigelow, Lynne Ramsey e Jane Campion. No caso de Bigelow, salienta-se o modo como o seu trabalho é sistematicamente associado ao nome do seu ex-marido James Cameron, num processo (consciente ou inconsciente) de diminuição do seu valor profissional. É na avaliação estilística de The Weigh of Water que Cobb lembra a controvérsia que o texto A Morte do Autor, de Roland Barthes, causou, numa altura em que uma leva significativa de mulheres e intelectuais de minorias étnicas tentavam afirmar-se como autores e académicos.

No terceiro capítulo Cobb concentra-se nos livros e filmes, oriundos dos EUA, que lidam com a questão da irmandade. A irmandade é vista como dispositivo narrativo e como mecanismo de validação autoral. Cobb avança uma das premissas importantes do seu livro: a (grande) necessidade de se escrever a história do cinema feito por mulheres sincronamente, enquanto acontece, antes que estes filmes sejam esquecidos pela historiografia convencional. Cobb pretende demonstrar como o trabalho colaborativo alicerça o potencial de a realizadora ser vista como autora. São, de seguida, tratadas as adaptações ao cinema de Mulherzinhas, de Louise May Alcott, e Os Divinos Segredos da Irmandade Ya-Ya, de Rebecca Wells, realizadas por Gillian Armstrong e Callie Khouri. Ambos os filmes tratam a busca da identidade e do amor, e a sua satisfação dentro das irmandades. Apesar de ambos conseguirem um relativo sucesso comercial nos EUA, Cobb não deixa de os criticar pelo tom com que subsumem políticas do feminino, nas relações de mulheres com mulheres. $\mathrm{Na}$ crítica ao filme de Khouri, Cobb mostra, igualmente, como se perpetuam estereótipos de representação da mulher afro-americana: ora assexuada, ora sobressexualizada.

No quarto capítulo, intitulado "Austen Pós-feminista: Por Mulheres, para Mulheres, de Mulheres”, Cobb discorre sobre várias adaptações ao cinema e à televisão de obras de Jane Austen, argumentando que esta profusão na produção Austeniana se deve à apreensão da escritora como símbolo de uma identidade feminina perdida. É neste capítulo que Cobb fala do "Chick Flick" (filme para mulheres jovens), referindo o modo como este género, quando realizado por um homem, se eleva, como se o tratamento do feminino pelo masculino supostamente transcendesse qualquer fórmula contida no tratamento do feminino pelo feminino. De forma paralela, no modo como a terminologia dos média funciona para desvalorizar intelectualmente o feminino, Cobb relembra o termo Janeite, atribuído às fãs de Jane Austen, que diminui intelectualmente o grupo que define. Cobb comenta o boom de adaptações de obras de Austen desde os anos noventa até aos dias de hoje, e sobre o modo como 
este corpo de trabalho tem levado a inúmeros debates sobre a escritora e o feminismo, nos quais o feminismo de Austen e uma Austen feminista ora são reivindicados, ora renegados ou recuperados, mostrando a sua ambivalência como emblema feminista. Aqui, volta também ao pós-feminismo, afirmando que a popularidade de Austen se deve a um conservadorismo inerente na autora e no pós-feminismo, e que a retração face aos avanços feministas é historicamente cíclica o recolhimento do feminismo é, perversamente, visto como emancipação, por uma nova geração que inicia o discurso com "Eu não sou feminista, mas...".

Nesta visão de Cobb, o pós-feminismo atual é, inerentemente, uma subjetivação que exclui o que fica para lá ou aquém da sociedade de consumo. Nestas narrativas, a emancipação feminina requer um emprego e uma subjetivação, independentemente da classe, do grupo étnico ou do comportamento sexual. E é por isso que uma crítica feminista ao cinema é fundamental, para perspetivar o debate saído de um cenário onde uma mulher ganhar o Grande Prémio de Cannes é uma raridade.

No último capítulo, o mais curto e onde arrisca uma conclusão, Cobb liberta-se de um certo espectro majoritário, tratando uma adaptação ao cinema, por uma cineasta afro-americana, da obra de uma escritora branca. E é esta dissonância que torna o (infelizmente mais curto) capítulo final no mais interessante. São aqui tocadas questões tão importantes como o ser duplamente difícil para cineastas de minorias étnicas a concretização de uma carreira como realizadoras; referindo-se Cobb a uma dupla desconfiança dos distribuidores de cinema em relação à mulher realizadora de minoria étnica.

O capítulo debruça-se sobre o filme A Vida Secreta das Abelhas (2008) por Gina Prince-Bythewood, baseado no livro homónimo da escritora Sue Monk Kidd. Como no capítulo anterior, o filme e o livro voltam a juntar-se na abordagem da questão da irmandade - neste caso uma irmandade de mulheres afro-americanas, no seio das quais se refugia uma jovem branca órfã de mãe, fugida a uma vida de violência doméstica às mãos de um pai alcoólico. Infelizmente, Cobb falha em não aprofundar os motivos que fizeram de A Vida Secreta das Abelhas um sucesso comercial, como livro e como filme, nos EUA. E, assim, no capítulo mais curto do livro se encapsulam os seus problemas: uma zona de conforto dentro da qual a autora se fecha e da qual se recusa a sair, não sabendo o leitor se por questões pessoais, se comerciais.

E no entanto, as questões afloradas são relevantes. Como o desconforto numa narrativa em que a mulher afro-americana é usada de forma fantasiosa como último reduto de bem-estar da mulher branca. 
O grande problema do livro é mover-se num campo estritamente anglo-americano, não cabendo no seu corpo exemplos de filmes e livros oriundos de outras culturas. Uma coisa é o estabelecimento de um campo de trabalho definido, uma outra é a insularidade de não sairmos desta definição para contrapormos outros cinemas no feminino. Neste livro, tanto as obras literárias como os filmes, existem suspensos numa bolha anglo-americana. Perfeito para se vender nestes mercados (e é presente a urgência no apelo ao mercado norteamericano), mas decepcionante para quem esperaria um estudo mais abrangente.

Mais ainda. Apesar de apresentar uma extensa bibliografia de indubitável utilidade, novamente o livro desaponta, no reduplicado paroquialismo das suas referências. Os exemplos que fogem a este padrão acabam por ser os já célebres de um Foucault ou de um Barthes.

O livro acaba por servir como um bom exemplo da fragmentação que existe entre o eixo anglo-americano e os outros, e como uma fatia de anglocentrismo, se assim o podemos pôr, que julgamos não ser inteiramente desejada pela autora. No fundo, o que este trabalho involuntariamente reflete é o domínio norte-americano do mercado da distribuição de cinema, afunilando-se o discurso em nome ou pelas pressões desse mesmo domínio.

A outra questão problemática do livro é o desconforto aparente no tratamento de questões minoritárias. Um desequilíbrio grave, na medida em que o cinema no feminino não se pode desligar de questões étnicas e de classe.

Ao mesmo tempo que Shelley Cobb levanta a questão da fragmentação na teorização do feminino, do feminismo e do papel da mulher realizadora, parece fechar-se num modo e num espectro anglo-americanos, que só se quebram no breve recurso aos cânones do chamado pós-estruturalismo continental. 